\title{
Induced Cell Death in a Thalamic Nucleus during a Restricted Period of Zebra Finch Vocal Development
}

\author{
Frank Johnson and Sarah W. Bottjer \\ Department of Biological Sciences, University of Southern California, Los Angeles, California 90089-2520
}

A discrete network of forebrain nuclei underlies vocal learning and production in male zebra finches. Three nuclei within this network form a neural pathway that is particularly important for vocal learning in juveniles: area $X$ of the avian striatum projects to the medial dorsolateral nucleus of the anterior thalamus (DLM), which in turn projects to the lateral magnocellular nucleus of the anterior neostriatum (IMAN). Lesions of any of these nuclei in juvenile birds disrupt normal vocal development, whereas the same lesions in adult birds have' no effect on already-learned song. Because numerous studies have shown that neuronal survival in the developing nervous system depends on access to efferent targets, we have investigated the possibility that the survival of DLM neurons is similarly regulated over the course of vocal learning. Thus, the efferent target of DLM (IMAN) was lesioned electrolytically in male birds at various stages of vocal development $(20,40,60 \mathrm{~d}$ of age and adult) and birds were killed either 2, 4, or 6 d postlesion. Electrolytic lesions of IMAN removed the single identified efferent target of DLM projection neurons and axotomized the terminal arborizations of these neurons. Although OLM does not normally lose neurons during vocal development, IMAN lesions in 20-d-old birds yielded numerous pyknotic cells throughout DLM by 4 d postlesion and a two-thirds reduction in DLM neuron density by $6 \mathrm{~d}$ postlesion. In contrast, IMAN lesions in adult birds had little or no effect on neuronal survival in DLM. Analysis of 40 -d-old birds revealed significant but less substantial cell loss than in 20-d-old birds, whereas 60-d-old birds were not different from adults. The age-related decline in the vulnerability of DLM cells to IMAN lesion-induced death suggests that factors that regulate DLM neuron survival may also be involved in the acquisition of learned vocal behavior in songbirds.

[Key words: songbirds, vocal learning, diencephalon, target deprivation, axotomy, pyknosis]

Neuronal survival in the developing nervous system depends on the interplay of several factors. Principle among these are access to efferent targets, arrival of afferent input, and the absence of an injury (e.g., axotomy) that might deprive developing neurons of pre- or postsynaptic contact. By the time the nervous system is mature, however, neurons typically show a reduced dependence on interaction with other cells, or none at all (for review, see Oppenheim, 1991). For example, whereas devel-

Received Aug. 31, 1992; revised Dec. 7, 1992; accepted Dec. 10, 1992.

Correspondence should be addressed to Frank Johnson at the above address.

Copyright (C) 1993 Society for Neuroscience $0270-6474 / 93 / 132452-11 \$ 05.00 / 0$ oping spinal motoneurons will dic if they do not establish contact with their postsynaptic targets, their survival depends on this contact only during a restricted phase of early life (Hamburger and Oppenheim, 1982). Similarly, it is also well established that presynaptic input is often necessary for the survival of developing, but not mature, neurons (Levi-Montalcini, 1949; Rubel et al., 1990).

Investigation of developmental factors that regulate neuronal survival has generally becn conducted in the context of understanding the phase of naturally occurring cell death that is characteristic of many developing neuronal populations (e.g., Cowan et al., 1984). By this view, early neuronal dependence on survival factors obtained from other cells may be a mechanism by which misplaced cells or connections are eliminatcd, or a simple way of matching the size of pre- and postsynaptic cell populations (Raff, 1992). However, evidence that some ncuronal populations do not undergo naturally occurring cell death (Armstrong and Clarke, 1979; Heathcote and Sargent, 1985), and the fact that many neuronal populations depend on efferent targets well beyond the phase of naturally occurring death (Snider and Thanedar, 1989; Crews and Wigston, 1990; Lowrie and Vrbova, 1992), raise important questions as to the mechanisms and significance of developmentally regulated neuron survival.

We are interested in understanding how neuronal survival is regulated during the development of three nuclei whose projection neurons form a serial pathway that contributes to vocal learning in songbirds (Fig. 1): area $\mathrm{X}$ of the striatum projects to the medial portion of the dorsolateral nucleus of the anterior thalamus (DLM), which in turn projects to the lateral magnocellular nucleus of the anterior neostriatum (IMAN). Lesions of any of these nuclei in juvenile birds prevent the development of normal vocal patterns, whereas the same lesions in adult birds do not influence the production of already-learncd song (Bottjer et al., 1984; Sohrabji et al., 1990; Scharff and Nottebohm, 1991; Halsema and Bottjer, 1992). Moreover, during the course of vocal learning (i.e., between 20 and $90 \mathrm{~d}$ of age), area X, DLM, and IMAN show contrasting profiles of morphological change: area $X$ increases in volume and adds new neurons (Bottjer et al., 1985; Nordeen and Nordeen, 1988), whereas DLM decreases in volume but does not lose neurons (Johnson and Bottjer, 1992), and IMAN both decreases in volume and loses neurons (Bottjer et al., 1985; Bottjer and Sengelaub, 1989; Korsia and Bottjer, 1989; for revicw, see Bottjer and Johnson, 1992; but cf. Nordeen et al., 1992).

In the present experiment we investigated the possibility that interactions between IMAN neurons and DLM projection neurons can regulate the survival of DLM neurons. Our strategy was to deprive DLM projection neurons of access to their target 
population by electrolytically lesioning IMAN in birds of various ages (this lesion removed IMAN neurons as well as the terminal arbors of DLM projection neurons, leaving a minimum of $2 \mathrm{~mm}$ of axon proximal to DLM somata). We report here that although DLM does not normally lose neurons during vocal development, electrolytic lesions of IMAN in 20-d-old birds induce substantial numbers of pyknotic cells throughout DLM by $4 \mathrm{~d}$ postlesion, and a two-thirds decline in DLM ncuron density by $6 \mathrm{~d}$ postlesion. In contrast, IMAN lesions in adult ( $>100 \mathrm{~d}$ old) birds have little effect on the survival of DLM neurons, while IMAN lesions in birds at intermediate stages of vocal development (40 and $60 \mathrm{~d}$ of age) reveal an age-related decline in the ability of IMAN lesions to induce cell death in DLM. These results suggest that the survival of DLM neurons can be influenced by terminal-arbor axotomy and/or blocking access to target neurons, but only during a restricted period of development that coincides with the acquisition of learned vocal behavior.

\section{Materials and Methods}

Subjects were male zebra finches obtained from our breeding colony. Vocal-control nuclei are distributed bilaterally throughout major subdivisions of the zebra finch brain (iclencephalon, diencephalon, mesencephalon, myelencephalon), and previous work has shown that they send and receive unilateral axonal projections primarily among themselves (Nottebohm et al., 1982; Bottjer et al., 1989; sce Fig. 1). Therefore, a significant advantage of this system is that if cxperimental manipulation of vocal-control nuclei is made unilaterally, contralateral nuclei serve as a within-subject control for the effects of the manipulation. In the case of DLM and IMAN, tract-tracing experiments using either in vivo labeling with horseradish peroxidase (Bottjer et al., 1989) or in vitro labcling with $1,1^{\prime}$-dioctodecyl-3,3,3',3'-tetramethylindocarbocyanine perchlorate (Johnson and Bottjer, 1992) indicate that IMAN is the exclusive target of DLM projection neurons. Thus, unilateral lesions of IMAN (and a surrounding parvicellular region; see below) remove all known target regions of ipsilateral DLM projection neurons.

Birds were removed from the aviary at various ages $(20,40,60 \mathrm{~d}$ of age and adult) and deeply anesthetized with Equithesin. Each bird was secured in a stereotaxic instrument and a midline incision was made over the dorsal surface of the skull. Using predetermined stereotaxic coordinates, small apertures were made in the skull overlying left and right IMAN. An electrode made of insulated nichrome wire (diameter, $210 \mu \mathrm{m}$; California Fine Wire Co.) was then lowered into left IMAN, and the nucleus was lesioned by passing $100 \mu \mathrm{A}$ of anodal current through the electrode for $2.5 \mathrm{~min}$. In birds from all age groups, these parameters were sufficient to produce complete lesions of IMAN and a surrounding parvicellular shell that also receives DLM afferents (Fig. $2 A$ ). In 20-d-old birds, the parvicellular shell extends only slightly beyond the Nissl-defined borders of IMAN. As the volume of IMAN declines with age, the surrounding parvicellular shell enlarges such that roughly the same volume of anterior neostriatum is occupied by DLM afferents in 20-d-old birds and adults (Johnson and Bottjer, 1992). The electrode was then repositioned and lowered into right IMAN, but no current was passed and the electrode was withdrawn after $2.5 \mathrm{~min}$. Following surgery, birds were removed from the stereotaxic instrument and the incision was closed with collodion. All 20-d-old birds were returned to their home aviaries to be fed by their parents, whereas older birds were housed singly or in same-age pairs in cages in which food and water were freely available.

Preliminary data from 20-d-old birds indicated that the presence of degenerating cells in DLM was maximal by $4 \mathrm{~d}$ following an ipsilateral IMAN lesion, and 20-d-old birds were therefore assigned randomly to one of three postlesion survival groups; they were killed either $2 \mathrm{~d}$ (group 20-2;n=6), $4 \mathrm{~d}$ (group 20-4;n=7), or $6 \mathrm{~d}$ (group 20-6;n=4) following surgery. All 40 - and 60 -d-old birds werc killed $4 \mathrm{~d}$ after the lesion (groups $40-4,60-4, n=7$ for both groups). In order to make direct comparisons with 20-d-old birds, adult birds were assigned randomly to one of two postlesion survival groups and were killed either $4 \mathrm{~d}$ (group A-4; $n=$ 4) or $6 \mathrm{~d}$ (group A-6; $n=4$ ) after the lesion. All birds were killed via an overdose of Equithesin and were exsanguinated with bird saline and

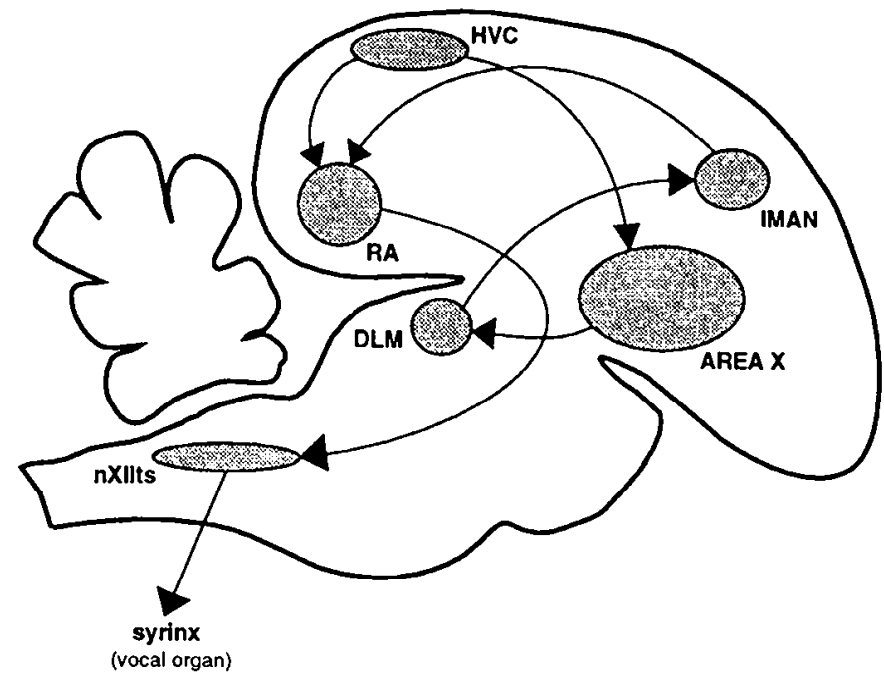

Figure 1. Schematic sagittal view of the some of the major song control nuclei and their axonal connections in male zebra finches. Three nuclei are particularly important for vocal learning: lesions of area X, DLM, or IMAN in juvenile birds prevent the development of normal vocal behavior, whereas lesions of these nuclei in adult birds have little or no effect on the production of already-learned song (Bottjer et al., 1984; Sohrabji et al., 1990; Scharff and Nottebohm, 1991; Halsema and Bottjer, 1992). $D L M$, medial portion of the dorsolateral nucleus of the anterior thalamus; $H V C$, higher vocal center; $I M A N$, lateral magnocellular nucleus of the anterior neostriatum; nXIIts, tracheosyringeal portion of the hypoglossal nucleus; $R A$, robust nucleus of the archistriatum.

perfused with buffered formalin. Brains were removed and allowed to postfix in buffered formalin for 7-10 d.

Brains were cryoprotected via immersion in buffered sucrose $1 \mathrm{~d}$ prior to cryostat sectioning. Alternate transverse sections (30 $\mu \mathrm{m}$ thickness) werc mounted onto gelatin-subbed glass slides, sections were stained with thionin, and the slides were coverslipped with Permount. Slides were then coded so that data analysis for each bird was done without knowledge concerning age or postlesion survival time.

For each bird, the density of neurons, degenerating cells, and cells undergoing mitosis was determined for both right and left DLM using a light microscope fitted with an ocular grid. Neurons were identified as generally possessing only onc spherical, basophilic nucleolus within a large transparent nucleus that was surrounded by darkly stained cytoplasm. The nucleolus was used as the unit of count (cf. Bottjer and Sengelaub, 1989; Johnson and Bottjer, 1992). In the event that a neuron containcd two nucleoli it was counted as a single cell, although the number of neurons with two nucleoli was low and did not vary among the groups. No correction factor was applied because the diameter of nucleoli was small $(1-2 \mu \mathrm{m})$ in relation to the section thickness $(30 \mu \mathrm{m})$. Degenerating cells were clearly distinguished by a single large sphere or several smaller globules of intensely stained, blue-black condensed chromatin. In some cases, the darkly staining chromatin globules were enclosed by a nuclear membrane and surrounded by cytoplasm, but clusters of chromatin globules that lacked a limiting nuclear membrane were also present. When present, the cytoplasm of degenerating cells was often more intensely stained than that of healthy neurons. Cells undergoing mitosis were identified by intensely stained, dark-blue strands of chromatin that were present in all four stages of mitosis (prophase, metaphase, anaphase, telophase). Examples of healthy neurons, degenerating cells, and mitotic figures are shown in Figure 3.

Quantification of cell densities was as follows: an ocular grid was aligned over the central portion of DLM and the number of neurons, degenerating cells, and mitotic figures present within the boundaries of the grid were entered into a microcomputer database. At final magnification, the volume encompassed by a single ocular grid was 0.0002 $\mathrm{mm}^{3}$ and 15 grids were counted per left and right DLM in each bird. For individual birds, the absolute number of cach class of cells was divided by the total volume of 15 grids to obtain the density of neurons, degenerating cells, and mitotic figures. Data for groups of 20 -d-old birds (groups 20-2, 20-4, 20-6) were compared for statistical significance with three separate analyses of variance (ANOVA; one for each class of cells). 

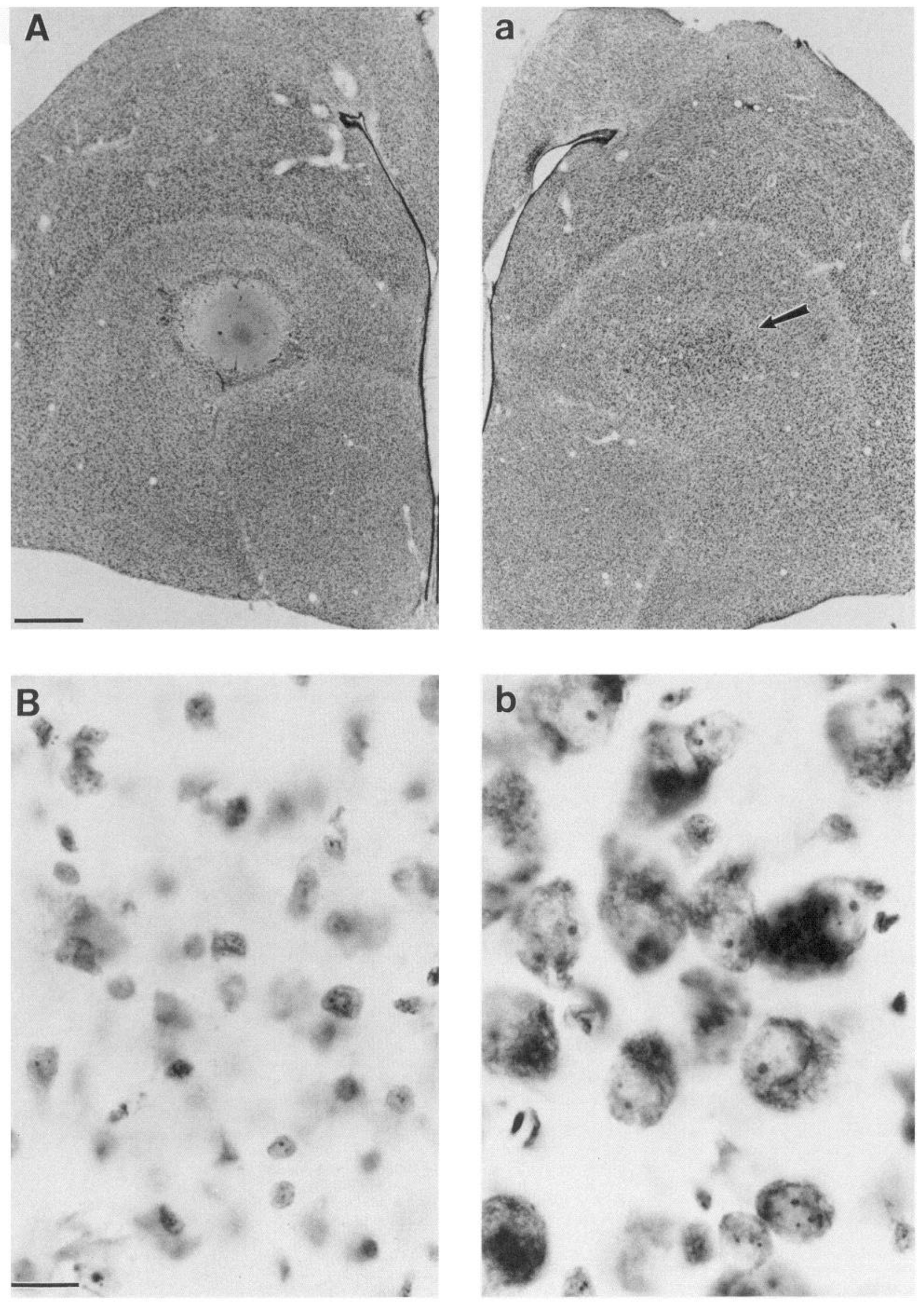
Data for age groups $(20-4,40-4,60-4, A-4,6)$ were analyzed in the same way.

\section{Results}

\section{Density of DLM neurons}

Effect of postlesion survival time in 20-d-old birds. Figure $4 \mathrm{~A}$ shows that unilateral IMAN lesions in 20-d-old birds decreased the density of neurons in ipsilateral DLM as a function of postlesion survival time. An ANOVA with postlesion survival time $(2,4$, or $6 \mathrm{~d})$ as a between-groups factor and ipsilateral versus contralateral DLM as a within-subjects factor revealed significant main effects of survival time $[F(2,14)=4.76, p<0.03]$ and ipsi-/contralateral DLM $[F(1,14)=211.23, p<0.0001]$. The interaction was also significant $[F(2,14)=41.45, p<0.0001]$. Planned comparisons showed that the interaction occurred because there was no ipsi-/contralateral difference in DLM neuron density in the 2 d survival group [20-2: $F(1,14)=2.00, p=$ 0.18 , whereas unilateral IMAN lesions significantly reduced DLM neuron density ipsilateral to the lesions in 4 and $6 \mathrm{~d}$ survival groups $[20-4: F(1,14)=115.29, p<0.0001 ; 20-6$; $F(1,14)=156.51, p<0.0001]$.

Planned comparisons also showed that there were no group differences in neuronal density within contralateral DLM $(F$ always $<1$ ). In contrast, the neuron density of ipsilateral DLM declined as a function of increasing survival time. That is, neuronal density of ipsilateral DLM in the $2 \mathrm{~d}$ survival group was greater than that of the $4 \mathrm{~d}$ survival group [20-2 vs $20-4: F(1,14)$ $=9.19, p<0.009]$, which in turn was greater than that of the 6 d survival group [20-4 vs $20-6: F(1,14)=10.66, p<0.006$ ].

Effect of age at time of unilateral IMAN lesion. Figure $4 B$ shows that the ability of unilateral IMAN lesions to decrease the density of neurons in ipsilateral DLM varied as a function of age. Because postlesion survival time ( 4 vs $6 \mathrm{~d}$ ) had no effect on any dependent measure in adult birds ( $F$ always $<1)$, data from the two adult groups were combined for all statistical analyses (A-4,6; $n=8)$. An ANOVA using age at time of lesion $(20,40,60 \mathrm{~d}$ old and adult) as a between-groups factor and ipsilateral versus contralateral DLM as a within-subjects factor revealed significant main effects of agc $[F(3,25)=5.56, p<$ $0.005]$ and ipsi-/contralateral $\operatorname{DLM}[F(1,25)=96.87, p<$ $0.0001]$. The interaction was also significant $[F(3,25)=26.57$, $p<0.0001]$. Planned comparisons showed that the interaction was due to a significant reduction in neuronal density within ipsilateral DLM of 20 - and 40-d-old birds $[20-4: F(1,25)=$ $118.99, p<0.0001 ; 40-4: F(1,25)=49.66, p<0.0001]$, whereas there were no ipsi-/contralateral differences in DLM neuron density among 60-d-old birds or adults [60-4: $F(1,25)=1.77$, $p=0.19 ; \mathrm{A} / 4,6: F<1]$.

Interpretation of the present data will be influenced by our previous finding that DLM neuron number does not change during vocal development (we found that DLM neuron density increased while DLM volume decreased; Johnson and Bottjer, 1992). Therefore, in order to determine whether this pattern of results was replicated in the present study, data for the neuron density of contralateral DLM in 20-d-old birds were combined (20-2, 20-4, 20-6, $n=17)$ and compared with the older groups of birds. Statistical analysis revealed a significant increase in neuronal density within contralateral DLM between $20 \mathrm{~d}$ of age and adulthood [20-d-old vs adult: $F(1,35)=8.36, p<0.007]$; 20-, 40-, and 60-d-old birds were not significantly different from one another [20-d-old vs 40-d-old: $F(1,35)=2.31, p=0.13$; 20-d-old vs 60-d-old: $F<1$; 40-d-old vs 60 -d-old: $F<1$ ]. We then randomly selected six 20 -d-old birds and six adults and measured the volume of contralateral DLM in each bird. This analysis revealed a decrease in DLM volume between $20 \mathrm{~d}$ of age and adulthood [0.08 and $0.05 \mathrm{~mm}^{3}$, mean volume of contralateral DLM for 20-d-old and adult birds, respectively; $F(1,10)$ $=22.96, p<0.001]$. DLM volume was then multiplied by neuron density to calculate neuron number in contralateral DLM for each bird. Because age-related changes in DLM neuron density and volume were inversely related, 20-d-old and adult birds had an equivalent number of DLM neurons (7957 and 7493, mean neuron number in contralateral DLM for 20-d-old and adult birds, respectively; $F<1$ ). These results replicate our previous finding that DLM ncuron number does not change during vocal development.

\section{Density of degenerating cells in DLM}

Effect of postlesion survival time in 20-d-old birds. Figure $5 \mathrm{~A}$ shows that unilateral IMAN lesions in 20-d-old birds influenced the density of degenerating cells in ipsilateral DLM as a function of postlesion survival time. An ANOVA with postlesion survival time as a between-groups factor and ipsilateral versus contralateral DLM as a within-subjects factor revealed significant effects of postlesion survival time $[F(2,14)=4.20, p<$ $0.04]$, ipsi-/contralateral DLM $[F(1,14)=19.11, p<0.0009]$, and the interaction of the two factors $[F(2,14)=4.15, p<0.04]$. Planned comparisons showed that the interaction was attributable to the absence of ipsi-/contralateral differences in the density of degenerating cells in DLM in 2 and $6 \mathrm{~d}$ survival groups $[20-2: F(1,14)=2.40, p=0.14 ; 20-6: F(1,14)=1.43, p=0.25]$ whereas the density of degenerating cells in ipsilateral DLM was significantly increased in the 4 d survival group [20-4: $F(1,14)$ $=29.10, p<0.0002$ ].

Planned comparisons also showed that there were no group differences among the low or zero density of degenerating cells in contralateral DLM in 20-d-old birds as a function of time following the lesion $(F$ always $<1$ ). In contrast, there was a sharp peak in the density of degenerating cells in ipsilateral DLM $4 \mathrm{~d}$ following the lesion. The $4 \mathrm{~d}$ survival group had a significantly greater density of degenerating cells in ipsilateral DLM than either the 2 or 6 d survival groups $(20-4$ vs $20-2: F(1,14)$ $=6.61, p<0.02 ; 20-4$ vs 20-6: $F(1,14)=5.09, p<0.04]$.

Effect of age at time of unilateral IMAN lesion. Figure $5 B$ shows that the ability of unilateral IMAN lesions to induce an increased density of degenerating cells in ipsilateral DLM varied as a function of age. An ANOVA with age at time of lesion as a between-groups factor and ipsilateral versus contralateral DLM

Figure 2. Unilateral lesions of IMAN produce dramatic changes in the cellular composition of ipsilateral DLM in juvenile zebra finches. $A$ and a, Low-power photomicrographs illustrate a unilateral electrolytic lesion of IMAN in a 20-d-old bird $(A)$ and the normal appearance of the nucleus in the contralateral hemisphere ( $a$, arrow). $B$ and $b$, High-power photomicrographs taken from the central portion of DLM in a 20-d-old bird that survived for $6 \mathrm{~d}$ following a unilateral lesion of IMAN illustrate the loss of neurons and increase in glia in ipsilateral DLM $(B)$ and the normal cellular composition of contralateral DLM $(b)$. The larger cells possessing one or two nucleoli within a large, round nuclear membrane are DLM neurons, whereas the smaller cells with granular, irregularly shaped nucleoli are glia. Scale bars: $A$ and $a, 500 \mu \mathrm{m} ; B$ and $b, 10 \mu \mathrm{m}$. 

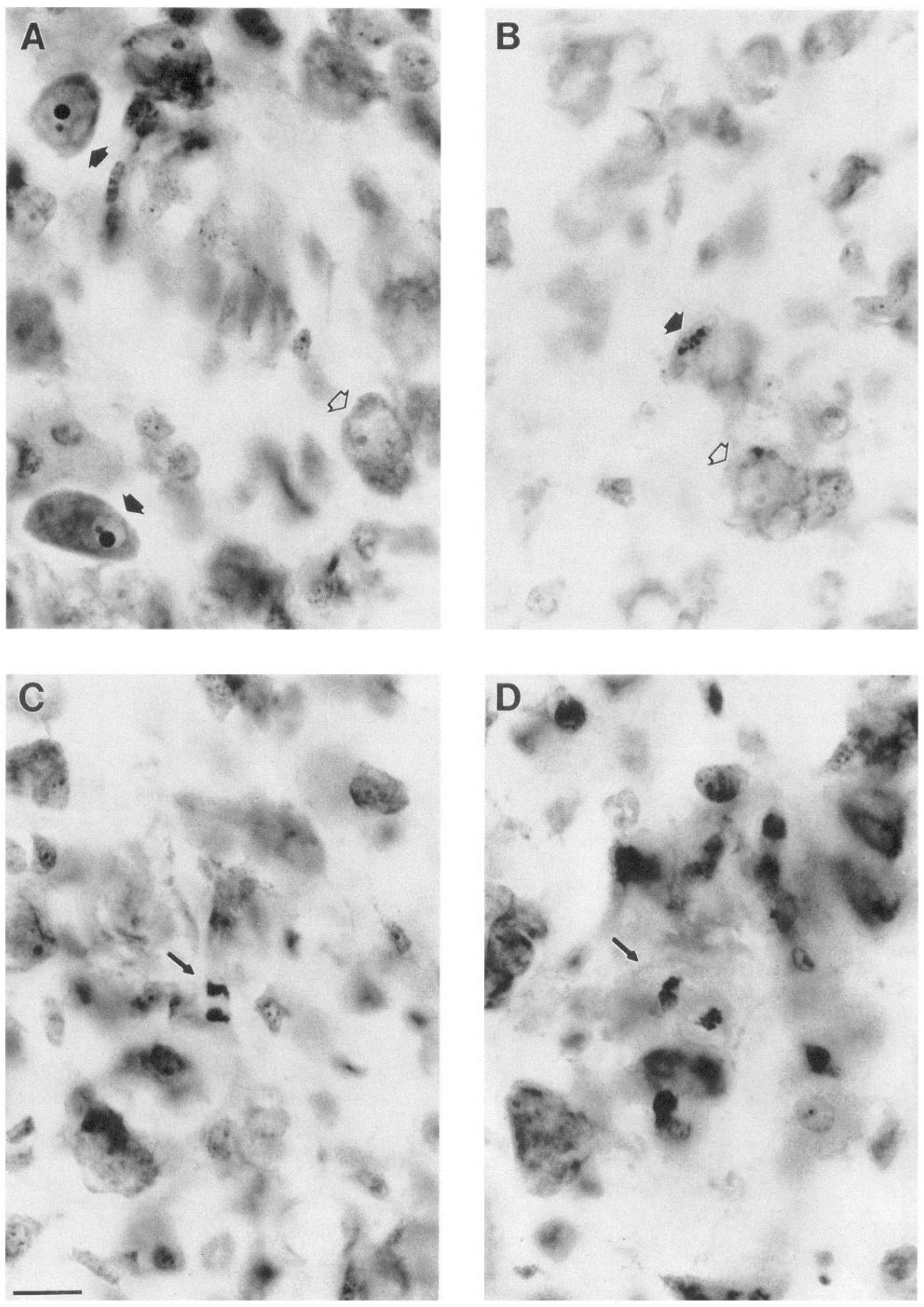


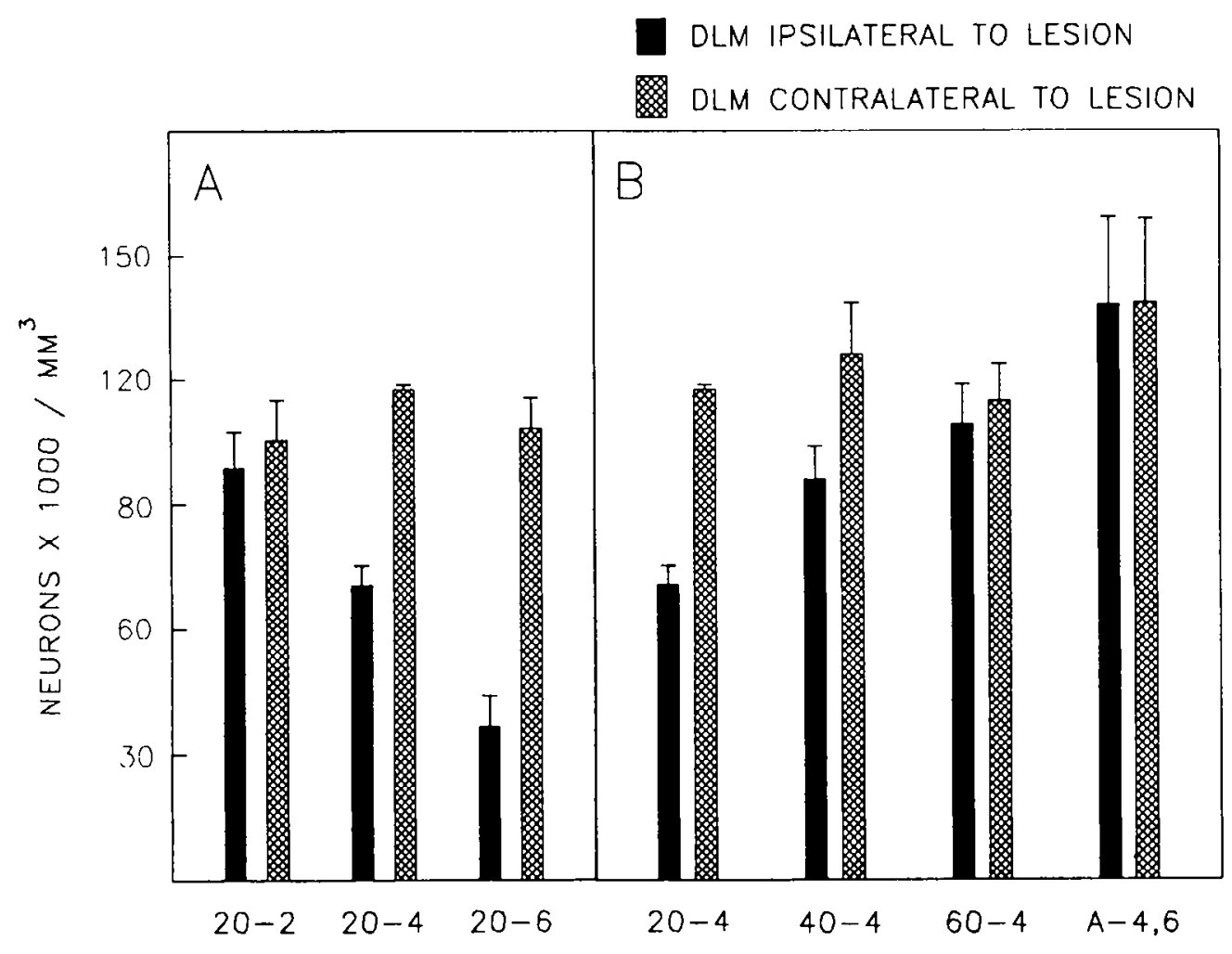

AGE AT TIME OF UNILATERAL IMAN LESION-DAYS OF SURVIVAL
Figure 4. $A$, Unilateral lesions of IMAN in 20-d-old zebra finches reduced neuron density in ipsilateral DLM as a function of survival time. Although there was no ipsi-/contralateral difference in the neuron density of DLM by $2 \mathrm{~d}$ postlesion, a two-thirds reduction in neuron density in ipsilateral DLM occurred by $6 \mathrm{~d}$ postlesion. Neuron density in contralateral DLM was unaffected by the lesions. $B$, The ability of unilateral IMAN lesions to reduce neuron density in ipsilateral DLM declined with increasing age. Whereas IMAN lesions reduced DLM neuron density in 20- and 40-d-old birds, the lesions had no effect on the DLM neuron density in 60-d-old and adult birds. Data are presented as means and SE. as a within-subjects factor revealed significant effects of age $[F(3,25)=14.78, p<0.0001]$, ipsi-/contralateral DLM $[F(1,25)$ $=39.52, p<0.0001]$, and of the interaction $[F(3,25)=13.68$, $p<0.0001]$. Planned comparisons showed that the interaction was due to a significant increase in the density of degenerating cells in ipsilateral DLM among 20- and 40-d-old birds [20-4: $F(1,25)=67.23, p<0.0001 ; 40-4: F(1,25)=10.49, p<0.004]$, whereas there were no ipsi-/contralateral differences in the density of degenerating cells among 60-d-old or adult birds [60-4: $F<1$; A-4,6: $F(1,25)=8.70, p=0.76$ ].

While there were no group differences in the low density of degenerating cells in contralateral DLM $(F$ always $<1)$, planned comparisons revealed that the density of degenerating cells in ipsilateral DLM was highest in 20-d-old birds [20-4 vs 40-4: $F(1,25)=12.69, p<0.002$ ]. In contrast, the difference between 40 - and 60-d-old birds was marginally significant [40-4 vs 60 4: $F(1,25)=3.51, p<0.07]$, and there was no difference between 60 -d-old birds and adults [60-4 vs A-4,6: $F(1,25)=8.24, p=$ 0.77 ].

\section{Density of mitotic figures in DLM}

Visual inspection of DLM in 20-d-old birds that received IMAN lesions indicated a substantial increase in the incidence of glial cells within $6 \mathrm{~d}$ of the lesion (see Fig. $2 B$ ). Although these cells could have migrated from regions outside the nucleus, another possibility is that these cells divided in situ. Because the cellular composition of DLM changes rapidly following an IMAN lesion (i.e., loss of neurons, increase in glia), it seemed likely that a small number of cells might be observed in the act of division if mitosis was at least partly responsible for the increase in the glial population. However, it should be noted that group differences in the incidence of mitotic figures in DLM will not necessarily indicate different rates of cell division; we cannot rule out the possibility that the time required for cell division varied among the groups and biased our ability to detect mitotic figures. The incidence of mitotic figures was measured in order to determine whether dividing cells were present within DLM, and to analyze how the appearance of mitotic figures might

Figure 3. Unilateral lesions of IMAN in juvenile zebra finches induce cell death and cell division in ipsilateral DLM. $A$, DLM cells undergoing the initial stages of lesion-induced pyknosis (solid arrows) possessed large intranuclear globules of condensed chromatin, but retained morphological characteristics that identified them as neurons (one or two nucleoli within a large, round nuclear membrane). Moreover, compared to healthy neurons (open arrow), the cytoplasm of pyknotic cells was often more intensely stained; note the large pool of intensely stained cytoplasm that surrounds the somewhat shrunken or compressed nuclear membrane of the pyknotic cell in the lower left. $B$, During later stages of lesion-induced pyknosis (solid arrow), a breakdown of intracellular structures occurred such that a nuclear membrane was no longer visible, the quantity of surrounding cytoplasm was greatly reduced, and the condensed chromatin had fragmented into clusters of smaller globules. A healthy neuron with two nucleoli is seen nearby (open arrow). $C$ and $D$, Cell division was often observed in DLM following lesions of IMAN. Shown here are examples of anaphase mitosis within DLM (arrows). Because IMAN lesions increased the size of the glial population in DLM (see Fig. 2B), these dividing celis are probably destined for a glial fate. Scale bar, $10 \mu \mathrm{m}$. 
Figure 5. A, Unilateral lesions of IMAN in 20-d-old zebra finches influenced the density of degenerating cells in ipsilateral DLM as a function of survival time. The density of degenerating cells in ipsilateral DLM was clearly highest in birds that survival for $4 \mathrm{~d}$ postlesion. This peak in the density of degenerating cells coincided with, and preceded, reductions in neuron density (see Fig. 4A). $B$, The ability of unilateral IMAN lesions to increase the density of degenerating cells in ipsilateral DLM declined with increasing age. The density of degenerating cells was highest in 20 -d-old birds, but a significant increase also occurred in 40-d-old birds. By comparison, IMAN lesions did not increase the density of degenerating DLM cells in 60-d-old birds and adults. Data are presented as means and SE.

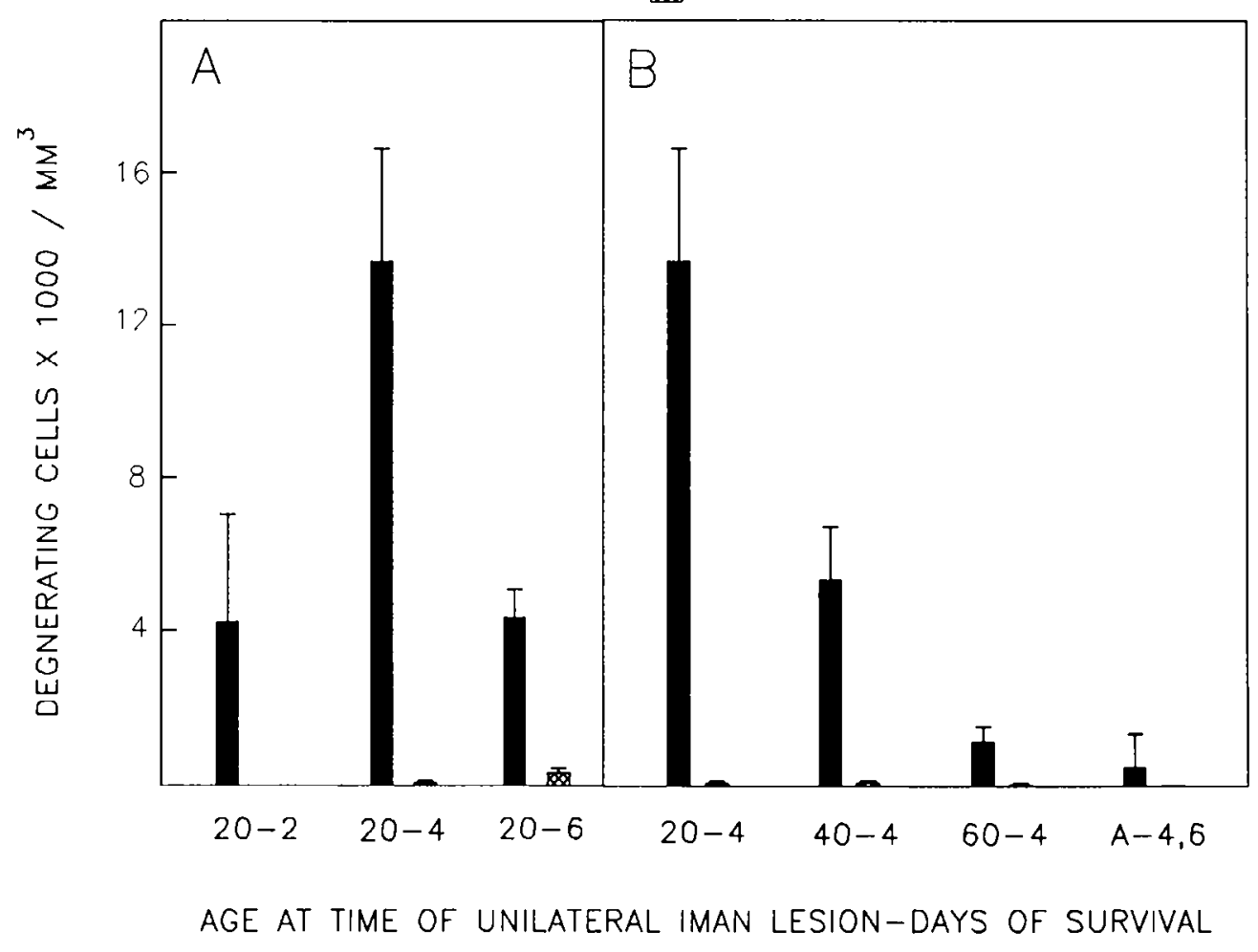

correspond to changes in the density of degenerating cells and live neurons.

Effect of postlesion survival time in 20-d-old birds. Figure $6 \mathrm{~A}$ shows the density of mitotic figures among groups of 20-d-old birds. Whereas mitotic figures were absent in the $6 \mathrm{~d}$ survival group, dividing cells were seen within DLM in 2 and $4 \mathrm{~d}$ survival groups, although their incidence was highly variable. As a result of this variability, an ANOVA with postlesion survival time as a between-subjects factor and ipsilateral versus contralateral DLM as a within-subjects factor indicated neither significant main effects [survival time: $F(2,14)=1.06, p=0.37$; ipsi-/ contralateral DLM: $F(1,14)=1.63, p=0.22$ ] nor a significant interaction $(F<1)$.

Effect of age at time of unilateral IMAN lesion. Figure $6 B$ shows the density of mitotic figures by age group. Although these data suggest that unilateral IMAN lesions were more effective in increasing the density of mitotic figures in ipsilateral DLM of younger birds, an ANOVA with age as a between-subjects factor and ipsilateral versus contralateral DLM as a withinsubjects factor revealed neither a significant main effect of age $[F(3,25)=1.56, p=0.22]$ nor a significant interaction $[F(3,25)$ $=1.18, p=0.34]$. However, the main effect of ipsi-/contralateral DLM was marginally significant $[F(1,25)=3.52, p<0.06]$, an indication that mitotic figures were more likely to be observed in ipsilateral DLM across age groups.

\section{Discussion}

The results of this experiment demonstrate that unilateral lesions of IMAN rapidly induce the death of ipsilateral DLM cells, and that the magnitude of induced death varies widely as a function of age, being most pronounced at $20 \mathrm{~d}$ of age and absent in adulthood. Similarly, whereas IMAN lesions in 20 -d-old birds decrease the density of DLM neurons by two-thirds, these lesions had no significant effect on the density of DLM neurons among adults. Comparison of the density of live neurons and degenerating cells among groups of 20 -d-old birds suggests that neuronal death accounts for the lesion-induced decline in the density of DLM neurons (Figs. $4 A, 5 A$ ). Although we cannot rule out the possibility that some DLM neurons may have migrated to new loci, the fact that a significant peak of lesioninduced DLM cell death (Fig. 5A, ipsi DLM, 20-4) coincided with a significant decline in neuronal density (Fig. $4 A$, ipsi DLM, 20-2 vs 20-4) and preceded a further decline in neuronal density (Fig. $4 A$, ipsi DLM, 20-4 vs 20-6) suggests that many DLM neurons were included among the dying cells. Indeed, pyknotic DLM cells that possessed morphological characteristics clearly indicative of a neuronal identity were consistently observed (i.e., cells with a basophilic nucleolus inside a translucent nucleus with a surrounding fringe of cytoplasm; see Fig. $3 A$ ).

IMAN lesions also tended to increase the density of mitotic figures in ipsilateral DLM, but this finding deserves cautious interpretation since the overall incidence of mitosis was quite low. However, because cell division generally occurs relatively quickly (within $1 \mathrm{hr}$; Darnell et al., 1986), a low incidence of mitotic figures would be expected under any circumstances; in fact, mitotic figures have never been reported in previous studies of normal developmental changes in cell number within songcontrol nuclei (cf. Bottjer et al., 1985; Nordeen and Nordeen, 1988; Bottjer and Sengelaub, 1989; Burek et al., 1991). While we do not know the eventual phenotypic identity of the dividing cells, the possibility that they will become neurons seems un- 


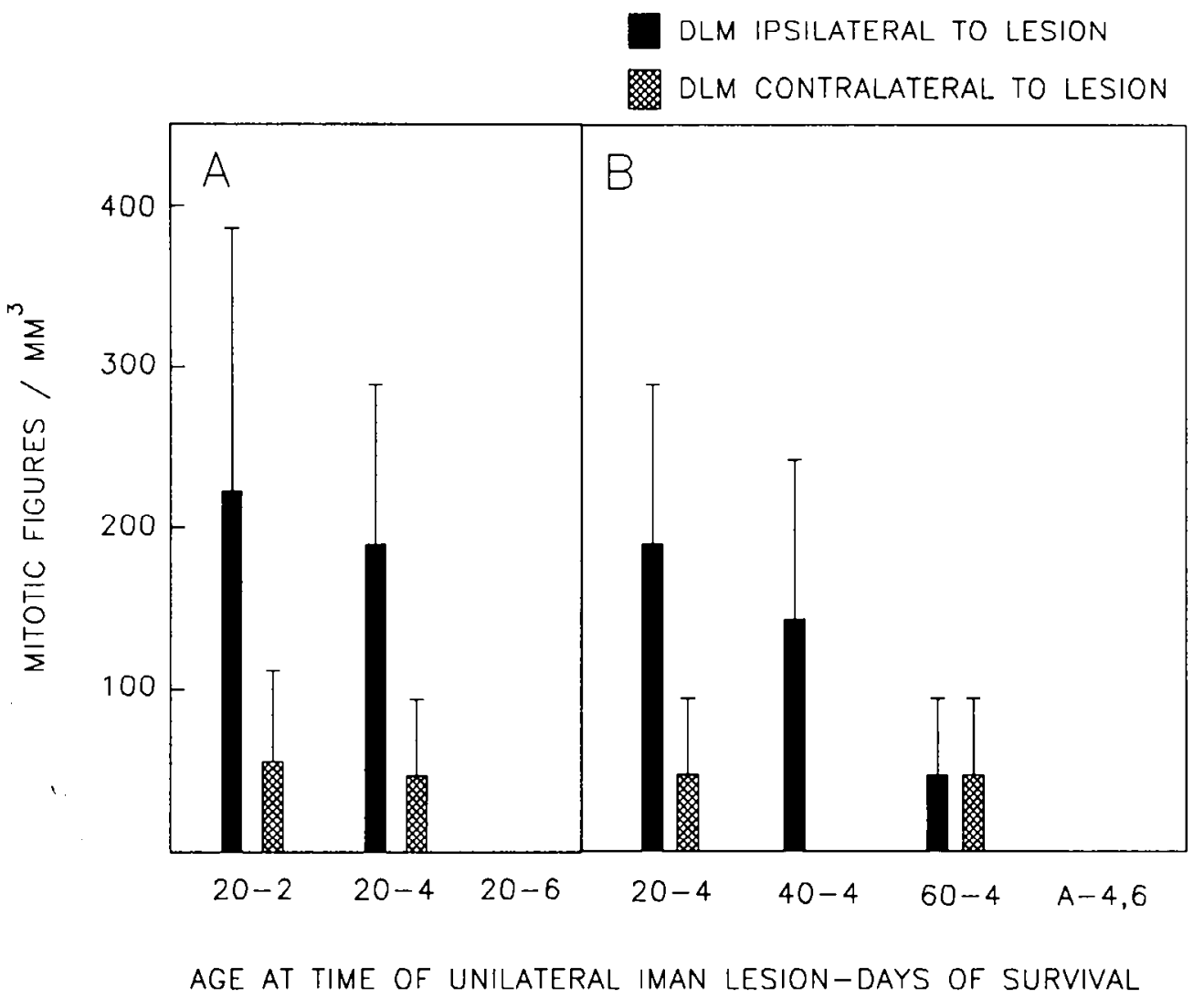

Figure 6. A, Unilateral lesions of IMAN in 20-d-old birds did not have statistically significant effects on the density of mitotic figures in ipsilateral DLM. Although it appeared that unilateral IMAN lesions increased the density of mitotic figures in ipsilateral DLM, this trend was not significant since variance estimates were large. $B$, The ability of unilateral IMAN lesions to influence the density of mitotic figures in ipsilateral DLM did not differ as a function of age, but IMAN lesions tended to increase the density of mitotic figures in ipsilateral DLM across age groups (see Results for details). Data are presented as means and SE. likely. It is well established that new neurons are generated in both juvenile and adult songbird brains, but such proliferation occurs along the ventricular zone (VZ) of the telencephalon and there are no reports of neural proliferation outside of the VZ (Alvarez-Buylla et al., 1990; Brown et al., 1993). In addition, newly generated neurons in adult birds migrate exclusively into telencephalic structures, and have never been observed within the diencephalon (Alvarez-Buylla and Nottebohm, 1988). Therefore, while the possibility of a neural fate cannot be ruled out, the dividing cells are in all likelihood destined for a glial fate. The ability of IMAN lesions in 20-d-old birds to induce an increase in DLM glial density (compare Fig. $2 B, b$ ) is suggestive evidence that the mitotic figures reflect the in situ proliferation of glia.

The lesion-induced increase in the glial population of DLM may be the result of a proliferative response to the additional space created by dying DLM neurons. Alternatively, greater numbers of glia may have been a response to the need for removal of cellular debris left by dying cells (in this case, the dividing cells could be microglia; see Thomas, 1992, for review). Glial populations have been observed to undergo similar changes in other instances of induced cell death (e.g., Bjorklund et al., 1986; Graeber et al., 1988). However, there are also recent demonstrations of increased glial growth in response to decreased levels of electrical activity and/or increased concentrations of extracellular $\mathrm{K}^{+}$(Canady et al., 1990; Canady and Rubel, 1992), and these conditions may have accompanied induced cell death in DLM and contributed to changes in the glial population. Interestingly, testosterone treatment stimulates glial proliferation in the adult songbird brain (Goldman and Nottcbohm, 1983) and scrum levels of testosterone in male zebra finches remain at detectable levels throughout juvenile development (Adkins-Regan et al., 1990). Together, these findings raise the additional possibility that endogenous levels of testosterone may have combined with the effects of IMAN lesions to stimulate glial proliferation.

\section{Mechanisms of induced DLM cell death}

Because both IMAN target cells and the terminal arbors of DLM projection neurons were removed by the electrolytic lesions used in this study, age-related changes in the ability of IMAN lesions to induce the death of DLM cells could be due to either developmental regulation of the sensitivity of DLM neurons to terminal-arbor axotomy, dependence on access to IMAN neurons, or both. Although future studies should allow us to discriminate between these possibilities, several recent studies suggest that axotomy and target deprivation induce death by similar mechanisms (Kashihara et al., 1987; Crews and Wigston, 1990; Oppenheim et al., 1990). In both instances, cell death is believed to occur because neurons are prevented from gaining access to target-derived neurotrophic factors (Lowrie and Vrbova, 1992).

However, whether induced cell death in DLM involves loss of access to target-derived factors or not, the morphology of pyknotic cells in DLM following lesions of IMAN is strikingly similar to that of cells undergoing naturally occurring death during the development of zebra finch song control nuclei (Bottjer and Sengelaub, 1989; Kirn and DeVoogd, 1989). For example, induced and naturally occurring death seem initially to involve the formation of large globules of condensed chromatin within the nucleus of an otherwise intact neuron. Subsequently, there appears to be a steady breakdown of intracellular structures, leading eventually to clusters of heterochromatic globules with- 
out a limiting membrane that are sometimes associated with tiny fragments of cytoplasm (cf. Fig. 3 in Kirn and DeVoogd, 1989, and Fig. 2 in Bottjer and Sengelaub, 1989). Morphological similarity between naturally occurring and induced cell death suggests that related mechanisms may underlie both modes of death.

During the course of the above comparisons, we observed many DLM neurons undergoing initial stages of induced death that possessed both a relatively normal-looking nucleolus and a large globule of condensed chromatin within a large. round nucleus (e.g., pyknotic cell in upper left of Fig. $3 A$ ). However, in most cases the cytoplasm of these neurons was intenscly stained, a characteristic indicative of increased levels of protein synthesis. As suggested by Martin and Johnson (1992), maintenance of normal nucleolar and nuclear morphology during the initial formation of intranuclear heterochromatic globules may indicate that RNA and protein synthesis continues and even participates in the ongoing process of cell death. There is clear evidence that both the death of cultured peripheral neurons deprived of NGF (Martin et al., 1988) and the target deprivation-induced death of spinal motoneurons (Oppenheim et al., 1990) involve RNA and protein synthesis. Therefore, the appearance of grossly normal cellular morphology and indications of increased protein synthetic activity during early stages of pyknosis raise the possibility that the induced death of DLM neurons is an active cellular process that requires the synthesis of new proteins.

One explanation for age-related differences in the ability of IMAN lesions to induce cell death in DIM is that the time course of induced cell death in adult birds is much slower than that in younger birds. If true, our $6 \mathrm{~d}$ survival time may not have been sufficient to document substantial death or loss of neurons in adult birds. This reasoning is consistent with the fact that a small but nonsignificant level of induced cell death was observed in the adult birds. To explore this possibility, we made visual inspections of DLM in adult birds that received IMAN lesions and were then allowed to survive for as long as 5 weeks. We found that the appearance of DLM in these birds was not observably different from DLM in normal adult birds, and a substantial loss of neurons similar to that evident in 20 -d-old birds was never seen.

\section{Relation of induced DLM cell death to morpholngical and physiological development}

The age-related changes in IMAN lesion-induced DLM cell death are of particular interest to us because they correspond to known changes in the morphological development of IMAN and DLM. For example, DLM declines in its Nissl-defined volume during vocal development, but undergoes an increase in neuronal density over the same period and therefore does not lose neurons (present results; Johnson and Bottjer, 1992). By comparison, IMAN declines in its Nissl-defined volume and loses neurons between 20 and 35-60 d of age (Bottjer et al., 1985. Bottjer and Sengelaub, 1989; Korsia and Bottjer, 1989; Johnson and Bottjer, 1992). Thus, DLM neurons are vulnerable to induced death at ages (20 and $40 \mathrm{~d}$ ) that precede and/or coincide with normally occurring changes in the volume and neuron density of DLM and in the volume and neuron number of IMAN.

In addition, we have recently found that the terminal field of DLM axons within and surrounding IMAN more than doubles in volume between 20 and $35 \mathrm{~d}$ of age, followed by an equally substantial regression between $35 \mathrm{~d}$ of age and adulthood (Johnson and Bottjer, 1992). With these findings in mind, the present results show that ability of IMAN lesions to induce DLM cell death is most pronounced at a time just prior to a dramatic expansion in the volume of anterior neostriatum that is occupied by DLM terminal arborizations. Therefore, the need target space in the anterior neostriatum (and/or associated neurotrophic factors) could be an important regulator of the growth of DLM axon terminals and IMAN lesions could induce the death of DLM neurons by preventing access to these targets. Indeed, the ability of DLM neurons to expand their terminal arborizations and acquire additional target space in the anterior neostriatum may be one reason why there is no naturally occurring neuron loss in DLM between $20 \mathrm{~d}$ of age and adulthood (Johnson and Bottjer, 1992; see Armstrong and Clarke, 1979, for related findings).

Because afferent input to a nucleus is often capable of mitigating the extent of target deprivation-induced cell death (Clarke, 1985; Linden and Pinon, 1987), the fact that IMAN lesions do not induce the death of all DLM neurons in 20 -d-old birds (neuron density was decreased by two-thirds) may be due to the presence of afferent input to DLM from area X. Similarly, a developmentally delayed or progressive ingrowth of afferent input from area $X$ could explain why IMAN lesions lose the ability to induce DLM cell death with increasing age. Area $X$ neurons provide the single identified input to DLM (Bottjer et al., 1989; see Fig. 1), but anterograde-labeling studies to determine the precise age at which this projection forms will be necessary to test these possibilities.

Interestingly, there are also known functional changes in the auditory response properties of IMAN neurons that correspond roughly to the age-related loss in the ability of IMAN lesions to induce DLM cell death. Single-unit electrophysiological recordings from area $X, D L M$, and IMAN in adult birds show that there are auditory neurons in all three nuclei that respond best to the bird's own song, whereas auditory neurons in area $X$ and IMAN in young (30-35-d-old) birds respond equally well to a variety of zebra finch song types and lack the song specificity of adult neurons (Doupe and Konishi, 1991, 1992). Therefore, because IMAN lesions induce significant levels of DLM cell death at a time when area $X$ and IMAN neurons have yet to acquire song-specific response propertics, factors that control cell survival may also be involved in auditory tuning of neurons in the X-DLM-IMAN pathway.

\section{Relation of induced DLM cell death to behavioral development}

Given evidence that lesions of area X, DLM, or IMAN disrupt vocal behavior only in juveniles, DLM neurons may acquire the ability to survive lesions of IMAN as the X-DLM-IMAN pathway becomes less and less important for vocal development. Although the exact time course over which lesions of area $\mathrm{X}$ and DLM lose the ability to disrupt vocal behavior has not been determined, the time course of lesion effectiveness for IMAN is known and is consistent with this idca. For example, Bottjer et al. (1984) lesioned IMAN in birds at various stages of vocal development and found that IMAN lesions lost effectiveness during the emergence of vocal stereotypy, between 55 and $60 \mathrm{~d}$ of age. Similarly, in the present study we found that IMAN lcsions induced DLM cell death and neuronal loss prior to, but not after, $60 \mathrm{~d}$ of age. Corresponding age-related changes in the ability of IMAN lesions to disrupt vocal learning and to induce DLM cell death may reflect distinct outcomes (one be- 
havioral, one cellular) that result from the disruption of common neural mechanisms. This hypothesis predicts that manipulations that extend the time course over which IMAN lesions impair vocal development (e.g., raising birds in visual isolation or treating juveniles with anti-steroid drugs; Morrison and Nottebohm, 1990; Brown and Bottjer, 1992) should also extend the ability of IMAN lesions to induce the death of DLM neurons.

A related possibility is suggested by behavioral analyses of vocal learning in songbirds. Young male zebra finches acquire their song by listening to and retaining a memory of the stereotyped vocalizations of an adult male. Acquisition of a song model begins around $20 \mathrm{~d}$ of age and is known as the sensory or auditory phase of vocal learning (Arnold, 1975). During a partially overlapping sensorimotor phase (30-90 d of age), young males rely on auditory feedback to modify initially variablc vocalizations so that a close match to the song model is eventually achieved (Immelmann, 1969; for review, see Slater ct al., 1988). With these processes in mind, the present results show that DLM neurons are most susceptible to IMAN lesion-induced death during the initial stages of auditory and sensorimotor learning. Therefore, mechanisms that regulate DLM neuron survival may be involved in the acquisition and/or early rehearsal of the song model on which adult vocal patterns will be based.

\section{References}

Adkins-Regan E, Abdelnabi M, Mobarak M, Ottinger MA (1990) Sex steroid levels in developing and adult male and female zebra finches (Poephila guttata). Gen Comp Endocrinol 78:93-109.

Alvarez-Buylla A, Nottebohm F (1988) Migration of young neurons in adult avian brain. Nature 335:353-354.

Alvarez-Buylla A, Theelen M, Nottebohm F (1990) Proliferation "hot spots" in adult avian ventricular zone reveal radial cell division. Neuron 5:101-109.

Armstrong RC, Clarke PGH (1979) Neuronal death and the development of the pontine nuclei and inferior olive in the chick. Neuroscience 4:1635-1647.

Amold AP (1975) The effects of castration on song development in zebra finches (Poephila guttata). J Exp Zool 191:26 I-278.

Bjorklund H, Olson L, Dahl D, Scwarcz R (1986) Short- and longterm consequences of intracranial injections of the excitotoxin, quinolinic acid, as evidenced by GFA immunohistochemistry of astrocytes. Brain Res 371:267-277.

Bottjer SW, Johnson F (1992) Matters of life and death in songbird forebrain. J Neurobiol 23:1172-1191.

Bottjer SW, Sengelaub DR (1989) Cell death during development of a forebrain nucleus involved with vocal learning in zebra finches. $J$ Neurobiol 20:609-618.

Bottjer SW, Meisner EA, Arnold AP (1984) Forebrain lesions disrupt development but not maintenance of song in passerine birds. Science 224:901-903.

Bottjer SW, Glaessner SL, Arnold AP (1985) Ontogeny of brain nuclei controlling song learning and behavior in zebra finches. J Neurosci 5:1556-1562.

Bottjer SW, Halsema KA, Brown SA, Meisner EA (1989) Axonal connections of a forebrain nucleus involved with vocal learning in zebra finches. J Comp Neurol 379:312-326.

Brown SD, Bottjer SW (1992) Blocking steroid hormones during song learning extends the sensitive period for lesions of IMAN in juvenilc male zebra finches. Soc Neurosci Abstr 18:529.

Brown SD, Johnson F, Bottjer SW (1993) Neurogenesis in adult canary telencephalon is independent of gonadal hormone levels. J Neurosci 13:2024-2032.

Burek MJ, Nordeen KW, Nordeen EJ (1991) Neuron loss and addition in developing zebra finch song nuclei are independent of auditory experience during song leaming. J Neurobiol 22:215-237.

Canady KS, Rubel EW (1992) Rapid and reversible astrocytic reaction to afferent activity blockade in chick cochlear nuclcus. J Ncurosci 12: 1001-1009.

Canady KS, Ali-Osman F, Rubel EW (1990) Extracellular potassium influences DNA and protein synthesis and glial fibrillary acidic protein expression in cultured glial cclls. Glia 3:368-374.

Clarke PGH (1985) Neuronal death during development in the isthmo-optic nucleus of the chick: sustaining role of afferents from the tectum. J Comp Neurol 234:365-379.

Cowan WM, Fawcett JW, O'Leary DDM, Stanfield BB (1984) Regressive events in neurogenesis. Science 225:1258-1265.

Crews LL, Wigston DJ (1990) The dependence of motoneurons on their target muscle during postnatal development of the mouse. J Neurosci 10:1643-1653.

Darnell J, Lodish H, Baltimore D (1986) Molecular cell biology. New York: Scientific American.

Doupe AJ, Konishi M (1991) Song selective auditory circuits in the vocal control system of the zebra finch. Proc Natl Acad Sci USA 88: 11339-11343.

Doupe AJ, Konishi M (1992) Song-selective auditory neurons emerge during vocal learning in the zebra finch. Soc Neurosci Abstr 18:527.

Goldman SA, Nottebohm F (1983) Neuronal production, migration, and differentiation in a vocal control nucleus of the adult female canary brain. Proc Natl Acad Sci USA 80:2390-2394.

Graeber MB. Tetylaff W, Streit WJ, Kreutzberg GW (1988) Microglial cells but not astrocytes undergo mitosis following rat facial nerve axotomy. Neurosci Lett 85:317-321.

Halsema KA, Bottjer SW (1992) Chemical lesions of a thalamic nucleus disrupt song development in male zebra finches. Soc Neurosci Abstr 18:1052.

Hamburger V, Oppenheim RW (1982) Naturally-occurring neuronal death in vertebrates. Neurosci Comment 1:38-55.

Heathcote RD, Sargent PB (1985) Loss of supernumerary axons during normal morphogenesis. J Neurosci 5:1940-1946.

Immelmann K (1969) Song development in the zebra finch and other estrildid finches. In: Bird vocalizations (Hinde RA, ed), pp 61-74. Cambridge: Cambridge UP.

Johnson F, Bottjer SW (1992) Growth and regression of thalamic efferents in the song control system of male zebra finches. J Comp Neurol 326:442-450.

Kashihara Y, Kuno M, Miyata Y (1987) Cell death of axotomized motoneurones in neonatal rats, and its prevention by peripheral reinnervation. J Physiol (Lond) 386:135-148.

Kirn JR, DeVoogd TJ (1989) Genesis and death of vocal control neurons during sexual differentiation in the zebra finch. J Neurosci 9:3176-3187.

Korsia S, Bottjer SW (1989) Developmental changes in the cellular composition of a brain nucleus involved with song learning in zebra finches. Ncuron 3:451-460.

Levi-Montalcini R (1949) The development of the acoustico-vestibular centers in the chick embryo in the absence of the afferent root fibers of the descending tracts. J Comp Neurol 91:209-242.

Linden R, Pinon LGP (1987) Dual control by targets and afferents of developmental neuronal death in the mammalian central nervous system: a study of the parabigeminal nucleus of the rat. J Comp Neurol 266:141-149.

Lowrie MB, Vrbova G (1992) Dependence of postnatal motoneurones on their targets: revicw and hypothesis. Trends Neurosci 15:80-84.

Martin DP, Johnson EM (1992) Programmed cell death in the peripheral nervous system. In: Apoptosis: the molecular basis of cell death (Tomei LD, Cope FO, eds), pp 247-261. Cold Spring Harbor, NY: Cold Spring Harbor Laboratory

Martin DP, Schmidt RE, DiStefano PS, Lowry OH, Carter JG, Johnson EM (1988) Inhibitors of protein synthesis and RNA synthesis prevent neuronal death caused by nerve growth factor deprivation. J Cell Biol 106:829-844.

Morrison RG, Nottebohm F (1990) Role of IMAN in post-critical period song learning in zebra finches. Soc Neurosci Abstr 16:1099.

Nordeen EJ, Nordeen KW (1988) Sex and regional differences in the incorporation of neurons born during song learning in zebra finches. J Neurosci 8:2869-2874.

Nordeen EJ, Grace A, Burek MJ, Nordeen KW (1992) Sex-dependent loss of projection neurons involved in avian song leaning. $J$ Neurobiol 23:671-679.

Nottebohm F, Kelly DB, Paton JA (1982) Connections of vocal control nuclei in the canary telencephalon. J Comp Neurol 207:344-357.

Oppenheim RW (1991) Cell death during development of the nervous system. Annu Rev Neurosci 14:453-501.

Oppenheim RW, Prevette D, Tytell M, Homma S (1990) Naturally occurring and induced neuronal death in the chick embryo in vivo 
requires protein and RNA synthesis: evidence for the role of cell death genes. Dev Biol 138:104-113.

Raff MC (1992) Social controls on cell survival and cell death. Nature 356:397-400.

Rubel EW, Hyson RL, Durham D (1990) Afferent regulation of neurons in the brain stem auditory system. J Neurobiol 21:169-196.

ScharffC, Nottebohm F (1991) A comparative study of the behavioral deficits following lesions of various parts of the zebra finch song system: implications for vocal learning. J Neurosci 1 1:2896-2913.

Slater PJB, Eales LA, Clayton NS (1988) Sung learning in zebra finches
(Taeniopygia guttata); progress and prospects. Adv Study Behav 16: 1-34.

Snider WD, Thanedar S (1989) Target dependence of hypoglossal motor neurons during development and in maturity. J Comp Neurol 279:489-498.

Sohrabji F, Nordeen EJ, Nordeen KW (1990) Selective impairment of song learning following lesions of a forebrain nucleus in the juvenile zebra finch. Behav Neural Biol 53:51-63.

Thomas EW (1992) Brain macrophages: evaluation of microglia and their functions. Brain Res Rev 17:61-74. 